\title{
P 146 THE USE OF DENSOSUMAB IN HOSPICE PATIENTS AND ITS EFFECT ON CALCIUM LEVELS
}

Karen Harvie, ${ }^{1}$ Ruth Isherwood, ${ }^{1}$ Judith Fraser ${ }^{2} .{ }^{1}$ Strathcarron Hospice, Denny, United Kingdom; ${ }^{2}$ Forth Valley Royal Hospital, Larbert, United Kingdom

\subsection{6/bmjspcare-2014-000654.187}

Background Bone is a common site of metastasis for many primary cancers. Denosumab is recommended for the prevention of complications in patients with bone metastases from solid tumours other than prostate cancer (NICE guideline 2012). In patients with breast cancer it has been found to be more effective, both clinically and economically, than alternative treatment options. It is administered as a subcutaneous injection 4 weekly. Hypocalcaemia is a known side effect of Denosumab occurring in $5.5 \%$ of patients overall, although little is known about who is most likely to experience this and the timing and severity of hypocalcaemia in relation to denosumab injection.

Aims To clarify prevalence and severity of the effect of denosumab on calcium levels in patients with breast cancer in our hospice population.

Methods We identified all patients with breast cancer currently under the care of the hospice in all settings: in-patients, day hospice and community. A retrospective audit of case notes was performed to identify those who had received densosumab using a standardised data collection tool. Laboratory computer results system was used to detect subsequent changes in calcium levels.

Results Forty-three patients with breast cancer were identified, 29 of whom have bone metastases. Six have received denosumab, 3 had hypocalcaemia following its administration- one patient had NCIC grade 2 hypocalcaemia, 2 patients NCIC grade 1 . All were initially managed with high-dose oral calcium supplementation but one required subsequent hospital admission for IV calcium. In this patient persistent hypocalcaemia precluded further denosumab doses. All had previously tolerated bisphosphonates.

Conclusions Our early experience with denosumab in this patient group suggests that hypocalcaemia may be more prevalent than thought. Further work is needed to clarify the timing of hypocalcaemia and need for blood monitoring and oral calcium supplementation. 